\title{
The Zhengzhou 27 Subway Station Under Fire Smoke Control Multiple Ventilation Mechanism Perfect Research
}

\author{
Guowei Liu, Jiahua Lu \\ College of Mechanical Engineering, Shanghai University of Engineering Science, Shanghai, China \\ Email address: \\ 952452641@qq.com (Guowei Liu), ljh-gcd@163.com (Jiahua Lu) \\ To cite this article: \\ Guowei Liu, Jiahua Lu. The Zhengzhou 27 Subway Station Under Fire Smoke Control Multiple Ventilation Mechanism Perfect Research. \\ International Journal of Science, Technology and Society. Vol. 5, No. 5, 2017, pp. 141-145. doi: 10.11648/j.ijsts.20170505.11
}

Received: July 6, 2017; Accepted: July 14, 2017; Published: August 10, 2017

\begin{abstract}
As an important facility of modern urban traffic, Metro has the characteristics of large passenger volume, high speed and accurate time. Therefore, in recent years, with the rapid development of urban rail transit construction in our country, the subway line length and passenger traffic volume have been increasing. But along with the development of subway traffic, fire accidents happen frequently. The subway with ventilation conditions, lighting conditions, characteristics of the internal environment is complex, fire safety evacuation and rescue work more difficult, so the fire safety design features of subway tunnel fire and tunnel has become a new research topic.
\end{abstract}

Keywords: Urban Traffic, Fire Accidents, Subway with Ventilation, Lighting Conditions

\section{Reasons}

There are many reasons for the subway fire, but generally speaking, there are six aspects:

1) vehicle factors. The subway locomotive itself due to a short circuit, carburetor fire, exhaust pipe fire caused by fire.

2 ) road factors. With the perennial subway tunnel rail traffic load, especially large hub sections, track quality serious decline, reduce friction, track irregularity and other bad risks increase, will seriously affect the braking distance, increase the risk of accidents.

3) driver factors. The driver's subjective initiative is an important factor in traffic accidents. Many accidents are caused by the driver's carelessness or non-compliance with the traffic rules.

4) passengers and belongings. Passengers smoking and carrying inflammable and explosive materials are also a very important factor in the fire [1].

5) terrorist incidents. In recent years, because of religious, nationalist differences and other reasons, terrorist organizations have begun to use bombs and other means to retaliate against governments, while the fire hazards and the possibility of the subway is the biggest.

6) natural and other factors, such as high temperature, rainfall, earthquakes, landslides and other natural disasters, are also some of the causes of fires.

\section{Evacuation}

\subsection{Evacuation Is Difficult}

(1) large passenger flow. As one of the main means of transportation in modern city, subway is popular and convenient for the public. According to statistics, the average daily passenger volume of Moscow Metro reached 8 million passengers, ranking first in the world, and the daily average passenger flow of Beijing Metro reached 1 million 250 thousand. Therefore, it is very difficult to organize evacuation in a fire accident [2]. (2) fewer ways to escape. The particularity of subway operation environment makes it easy for passengers to escape. The subway has less safe exit, and is generally used as a two-way passageway. In addition, there is no vertical elevator for passengers and no emergency shelter. (3) long escape distance [3]. In Shanghai people's Square subway station as an example, the station has 12 entrance, 5 of them through the ground, 7 channels connected underground shopping malls (the middle 4 channel is provided with a fire shutter), there are 10 escape at a distance of $100 \mathrm{~m}$ more than 12 evacuation routes, as far as $260 \mathrm{M}$, once a burst the fire accident in the subway personnel trapped victims of the possibility of considerable; (4) obstructions. In general subway entrance set automatic checking device, fire will 
seriously hamper the personnel evacuation, evacuation personnel delay time [4]. The subway structure is a relatively closed underground system. After the fire, the rescue work is very difficult. A lot of smoke in the fire, the fire commanders to quickly determine the fire point; high temperature flue gas heat radiation and the blast effect, making it difficult for the firemen to close the fire point; ventilator time limit, the firefighters to rescue the scope of activities is limited; the import and export of a single, the firefighters between difficult tactics, megasporocyte; the use of fire extinguishing agent limited, Halon 1211, 1301 and good effect of $\mathrm{CO}_{2}$ fire extinguishing agent, in use process will produce toxic or harmful gases, not easy to use fire in underground space. 1.2 reasons caused by subway fire since the subway is put into use the fire has never been interrupted, the main reason has the following points: (1) the subway tunnel in illegal operations; (2) passenger car safety in violation of the relevant provisions, carrying inflammable goods on board or smoking in the car ; (3) electric circuit; (4) arson; (5) other reasons. Subway fire safety engineering construction of 2 subway fire prevention includes subway fire safety design and daily safety management, mainly reflected in the establishment of subway fire monitoring and alarm system, smoke control system, water supply system, fire evacuation and rescue system and other aspects.

\subsection{Alarm System}

The fire monitoring and alarm system of metro, the composition of monitoring and alarm system, the subway fire monitoring and alarm system is set up according to the two monitoring methods. The first level is the central control room, centralized monitoring and management of all alarm system, keep abreast of all dynamic situation; the second level for the station control room, are respectively arranged in the subway station, is the alarm subsystem, within the jurisdiction of the state of fire monitoring and alarm, and can be implemented the fire linkage control operation, and the alarm system and the monitoring equipments are connected into network circuit, ensure the alarm signal sending the detection point timely, correctly and smoothly arrive at all levels of the monitoring center.

\subsection{Platform Design}

Subway fire monitoring and alarm system classification, according to the use of equipment, environmental conditions, the system can be divided into: (1) on-site fire monitoring and alarm equipment. Including: a) fire sensor for station equipment room, station hall, platform of public passenger areas such as automated detection of fire; b) manual alarm, passenger station equipment placed in public areas, and regional train room, to promptly notify the fire; c) the temperature sensing cable, cable interlayer monitoring platform layer power for the d); emergency telephone jack, fire hydrant box configuration in the passenger station equipment public areas, housing area, tunnel and station settings on the outside; (2) fire monitoring and alarming equipment for station dispatching room. Including: (a) alarm controller, can be monitored at any time to accept the alarm signal of each detection point, issue audible and visual alarm signal, and can be automatic or manual execution, the implementation of joint control of fire control facilities; B) graphic display terminal, according to the station building plane grade and section shows detailed information of the system, including fire alarm equipment installation location, location, equipment running status, fault alarm and fire fighting facilities related action signal, and real time print related data report; c) video transmission system. Full range monitor installation platform at the station, the station hall and other public places, the station to collect real-time video information, and reflect to the CCTV Monitor duty room, by the staff on duty monitoring and processing; (3) the central control room fire monitoring and alarm device of graphic display terminal, with the function of graphic display station terminal [5]. The smoke control system when subway tunnel fire, the greatest danger is not the fire itself (flame and high temperature), but can quickly spread to the flue gas in the tunnel, it will reduce the visibility and the trapped people died of suffocation. Tunnel fire research shows that how to build efficient smoke control system and control fire smoke diffusion is the key [6]. The composition of smoke control system and the smoke control system for running subway include tunnel fan, electric air valve, impulse fan and nozzle. The smoke control of the subway is realized by the positive or reverse of the tunnel fan and the coordination, closing or opening of the electric air valve. Because of the special structure of metro station, it is difficult to set up an independent smoke exhaust system, so it is necessary to combine the smoke exhaust system with the normal ventilation system. When the fire happens, the ventilation system will be transformed into a smoke exhaust system. Since the amount of exhaust smoke is much larger than that in normal operation, the dual speed fan is generally used, which operates at low speed under normal ventilation and runs at high speed when smoke is exhausted. When the station fire accident, the fire ventilation mode for operation: (1) the station hall layer of fire, then closed the station hall layer of air supply system and the platform layer / exhaust system, the station hall layer / exhaust system exhaust outlet flue gas will be discharged to the ground, the fresh air through the station exit from the outside into the station hall, so as to facilitate the evacuation from the entrance to the ground; (2) the platform layer when there is a fire, close the platform layer of air supply system and station hall layer / exhaust system, the platform layer / exhaust system exhaust outlet flue gas will be discharged to the ground, while the staircase platform the export layer form negative pressure and downward airflow, easy evacuation at the station hall layer, in order to prevent the flue gas by pressure flow to the station hall, stairs down air speed control in general should be more than $1.5 \mathrm{~m} / \mathrm{s}$. Setting up the model of smoke control, subway fire accidents can usually be divided into two kinds: station fire and interval tunnel fire. When the train is running in the tunnel, there will be a fire, and the train should be opened to the nearest station 
to evacuate passengers. It can be handled according to the fire condition at the station. Taking an actual engineering subway train fire as an example, the optimal ventilation and smoke exhaust model is discussed by means of theoretical analysis and computational fluid dynamics (CFD) [7] numerical simulation analysis.

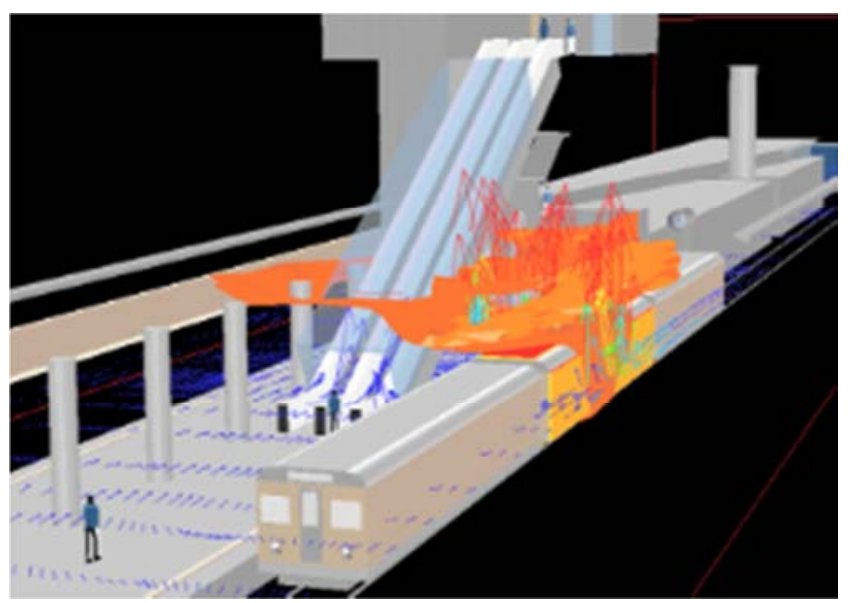

Figure 1. Subway train fire as an example.

\section{Data Analysis}

The platform when fire is mainly depend on the arrangement on both ends of a platform under normal condition of the outlet of exhaust gas, due to centralized arrangement of exhaust port, the effect of different operation modes of ventilation and smoke exhaust fan vary greatly, but also train fire in different position, will also affect the effect of smoke. Therefore, the need for different fire position, how to mobilize the research platform fan to ensure a safe area and the largest evacuation channel. CFD software can be used to simulate the airflow field and temperature field in the case of fire, which provides a favorable means for the research and analysis of reasonable fan operation mode. A) when the fire accident, the fan running and steering should be according to the actual situation of the fire to determine; $b$ ) if the middle of the train fire, take the advice of the fan site for ventilation purposes; c) if the head of the train fire, suggestions to open the exhaust fan near the fire one side, the other end of the air machine closed, open at the same time a nearby fire interval fan site or fan exhaust [8]. The establishment of 2.2.3 smoke prevention zone, when the fire occurs, the smoke will lead to trapped personnel poisoning, or even suffocation casualties, so the smoke control system in the subway project is particularly important. Hall and platform, the equipment room and control room management station smoke volume at $1 \mathrm{~m} 3 /$ general station (min? M 2) design; tunnel in the tunnel section of the flue gas velocity should be less than $2 \mathrm{~m} / \mathrm{s}$ and not more than $11 \mathrm{~m} / \mathrm{s}$, so as not to affect the evacuation [9]. A subway station in Guangzhou as an example, consider the design according to the 2023, the early peak hour traffic of 15 thousand people, the station hall and video rate decreased for 120 s within the range of $80 \mathrm{~m}$ did not escape the combustion zone personnel is dangerous [10], but the evacuation speed is $1.3 \mathrm{~m} / \mathrm{s}$ and $80 \mathrm{~m}$ within the scope of the staff the escape time is only about 60 s, so the automatic sprinkler system is feasible. Set the automatic sprinkler system can significantly reduce the ignition point temperature, so the heat is "average" assigned to the other position of the tunnel area, which the lag time of about $150 \mathrm{~s}$, for the trapped escape from the fire; automatic sprinkler system is set up [11], so that heat is not concentrated at the top of the tunnel damage accumulation at the top the strength of the concrete structure, so as to protect the tunnel structure, so the installation of automatic sprinkling fire extinguishing system in metro tunnel can improve the safety and reliability of [12].

Gas fire extinguishing system has made a comprehensive survey of the development and application of gas fire extinguishing systems both at home and abroad, and dozens of them have been put into use the establishment of a sound shelter facilities, refuge facilities can not only provide protection for people who escape, but also for firefighters temporarily escape smoke and hot air [13]. In the design of the middle and long subway tunnels, the safety shelter should be taken into account, the layout of the passageway, the distribution of compartments and space, and the needs of the corresponding auxiliary facilities. As usual the main adit for inspection, repair and maintenance of the road tunnel and contact the local repair vehicle, and change the direction of the transition channel; the fire and other emergency situations, you can take a temporary evacuation, adit safety evacuation and fire rescue channel. But studies show that when trapped in the fire, though trapped, the heat and smoke leaks eventually lead to death.

Therefore, the minimum fire limit of a safe shelter shall be insulated from smoke and should be considered in addition to the fire resistance of the tunnel structure, and independent ventilation systems shall be considered in these areas. Pedestrian crosswalk set fire shutter and its structure and construction technology of tunnel shall meet the following requirements: the door seams, guide, drum gap to have fire smoke sealing measures to prevent smoke from entering; setting the on-off device on both sides of the fire shutter, and can achieve automatic, manual and mechanical control. Ensure emergency use; fire resistance fire shutter should not be less than 3 hours.

The rectification of the subway fire hazards, and some of the subway operators symbiotic fire unsafe factors: newsstand and all kinds of shops, ventilation booth around the illegal construction, over the age of old passenger cars and so on. Although the newsstand and various shops can create short-term benefits, but the potential for greater risk of fire; ventilation Pavilion around the illegal construction, with major fire hazards, once the fire will escape the manufacturing difficulties, development and even increase fire; ultra life service of the old bus in the process of operation is probably the main reason fire. Therefore, all the above fire hazards should be resolutely corrected or banned, so as to ensure the safe operation of the subway [14].

The establishment and perfection of the subway safety management information system research and development of 
metro safety accident statistics system, subway safety policies and regulations of the retrieval system, the MTR safety expert database system, the subway safety supervisory system; establishing information system of safe production, in order to improve the level of production safety supervision of iron heights.

Safety evaluation and conduct regular safety inspections of the subway system, safety evaluation and make qualitative and quantitative, timely find and solve the existing subway system in accidents, the accidents occur and may cause the loss of the lowest.

Conclusion in summary, the subway tunnel is different from the general architecture of the underground, complex terrain, closed structure, staff mobility, once the fire happens to people's life and property damage will have a serious negative effect. This article from the characteristics of subway fire and

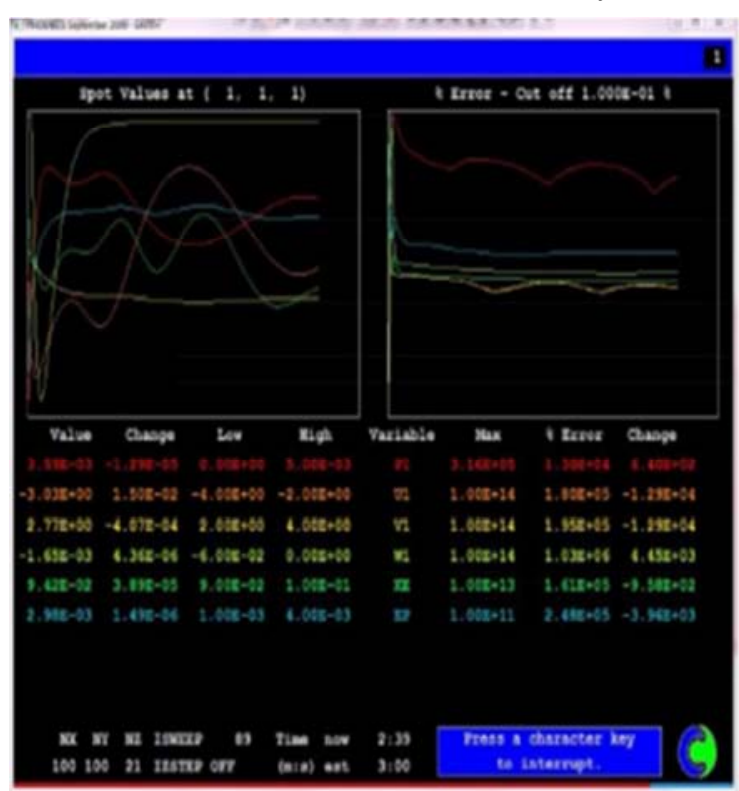

the causes of the angle of analysis for subway fire monitoring and alarm system, smoke control system, water supply system, fire evacuation and rescue system, puts forward some ideas for strengthening the safety inspection and rectification of fire safety. Fire safety engineering and construction of Metro future development put forward some opinions: the development of advanced subway fire monitoring and alarm system; smoke control system, fire water supply system to improve the subway; the development of advanced environmental protection, safety and economy of the subway fire extinguishing system; evacuation mode improved the subway, to provide protection for the evacuation work of subway fire fighting and the trapped personnel; adopt advanced management technology, improve the daily management of the subway.

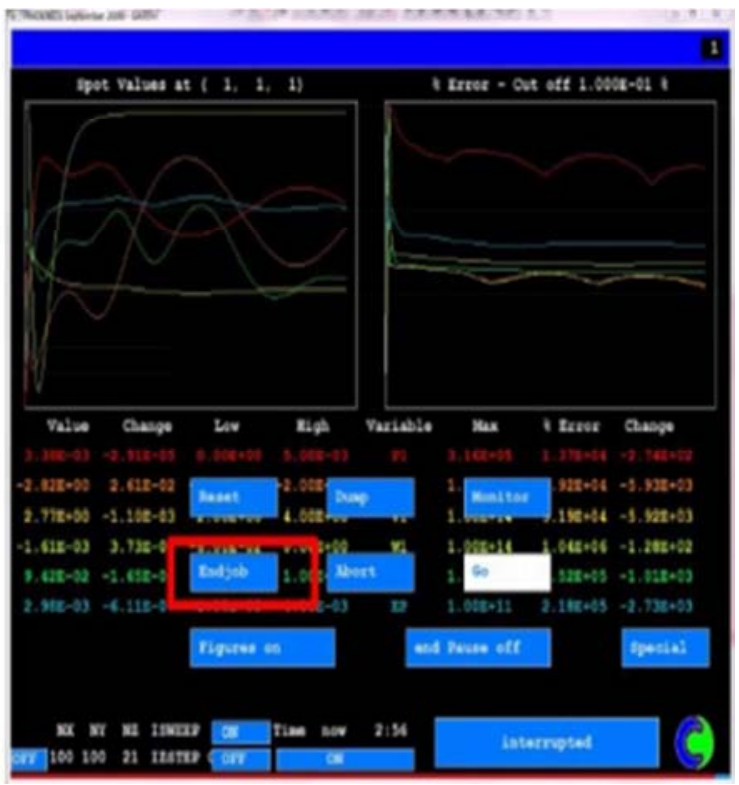

b

Figure 2. Computing process interface.

\section{Conclusion}

Through numerical simulation analysis, we can find that the large space of the terminal hall has a great capacity of storing smoke, so that the smoke will not fall to dangerous height in a short time, and it will be less harmful to people. The top of the big space is reasonably equipped with an electric shutter and a natural smoke exhaust port, which can keep enough smoke height in the evacuation time, and no need to install a large power mechanical smoke exhaust device. Reduce fire investment and increase the economic benefits of commercial buildings. In view of the breakdown of glass under high temperature conditions, large space glass curtain walls and roofs should be specially treated to increase the temperature of the crushing of glass, thereby increasing the available evacuation time to a great extent. It is difficult to measure the fire development data through the laboratory, and computer simulation is a complement to the experimental method.

\section{Funding}

This work was supported by Program of Shanghai College Construction [14110501200].

\section{References}

[1] Lie T T, Caron S E. Fire resistance of hollow steel columns filled with silicate aggregate concrete: test results [R], Ottawa, Canada: NRC-CNRC Internal Report. No. 570, 1988.

[2] Lie T T, Chabot M. Experimental studies on the fire resistance of hollow steel columns filled with plain concrete [R], Ottawa, Canada: NRC-CNRC Internal Report. No. 611, 1992.

[3] Lie T T. Fire resistance of circular steel columns filled with bar-reinforced concrete [J]. Journal of Structural Engineering, 1994, 120 (5): 1489-1509.

[4] Average Control For Simusoidal-And Random-Vibration Testing, Usher. T. J. Aeoust, Soe, Amev, Vol 41 no. 4. 
[5] GB/T 2423.10:2008 environmental testing for electric and electronic products part second: Test methods test $\mathrm{Fc}$ and guidance: vibration (sinusoidal).

[6] IEC 60068-2-6:2007 testing - Part Tests - Test Fc: Vibration (sinusoidal) 2-6: (Environmental).

[7] Lizi Xu. Reliability analysis of substation automation system [J]. Power System Technology, 2002, 26 (8): 68-72.

[8] Xiaofeng Wu. Hao Zhang. Development of digital processor based measuring and controlling unit for intelligent breaker [J]. Power System Technology, 2003, 27 (7): 70-74.

[9] Nochumson C J. Disscussion of'survey results of low-voltage circuit breakers as found during maintenance testing: working group report" [J]. IEEE Trransaction on Industry Applications, 1997, 33 (5): 1370-1371.

\section{Biography}

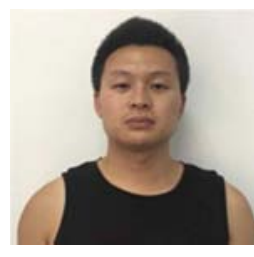

Guowei Liu was born in December 1992 in Shandong Province. He has got a bachelor's degree of material forming and control engineering in Linyi university in 2015 and now he is a postgraduate in Shanghai University of Engineering Science.
[10] Billinton R, Allan R N. Reliability Evalution of Engineering Systems. London [M]: PITMAN B 00 KS LIMITED, 1983.

[11] Kodur V K R, Lie T T. Evaluation of fire resistance of rectangular steel columns filled with fibre-reinforced concrete [J]. Canadian Journal of Civil Engineering, 1997, 24: 339-349.

[12] Lie T T, Stringer D C. Calculation of the fire resistance of steel hollow structural section columns filled with plain concrete $[\mathrm{J}]$. Canada Journal of Civil Engineering, 1994, 21 (3): 382-385.

[13] Hass R. On realistic testing of the fire protection technology of steel and cement supports [R], Melbourne, Australia: Translation BHPR/NL/T/1444, 1991.

[14] Kodur V K R. Performance of high strength concrete-filled steel columns exposed to fire [J]. Canadian Journal of Civil Engineering, 1998, 25: 975-981.

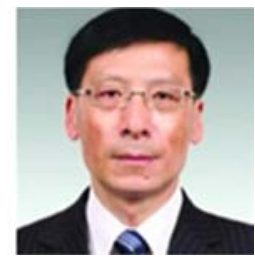

Jiahua Lu is professor of Mechanical Engineering College of engineering. The main research interests include turbomachinery, thermodynamics, and numerical experiments of multiphase fluid dynamics. 